\title{
BRIGANTIA DE BIRRENS: \\ INTERAÇÕES CULTURAIS EM ZONA DE FRONTEIRA \\ NA BRITÂNIA ROMANA
}

Ismael Wolf ${ }^{1}$

RESUMO

O presente artigo apresenta uma análise da imagem de Dea Brigantia de Birrens, na Britânia, provavelmente datada do século II d.C., abordando seu material, seu contexto, sua composição, seus elementos e significados, em uma abordagem que abrange tanto a imagem quanto a inscrição que formam a obra visual. São investigadas possíveis conexões com outras formas de culto, traços de interações culturais e os impactos causados sobre a população indígena bretã.

PALAVRAS-CHAVE

Brigantia; Britânia Romana; Muralha de Adriano; Religião; Império Romano.

\footnotetext{
${ }^{1}$ Mestre em História Social da Cultura pela Pontifícia Universidade Católica do Rio de Janeiro. Especialista em História Antiga e Medieval pelo Núcleo de Estudos da Antiguidade da Universidade do Estado do Rio de Janeiro e em Saberes e Práticas na Educação Básica (Ensino de História) pela Universidade Federal do Rio de Janeiro. Licenciado em História pela Faculdade Porto-Alegrense e Bacharel em História pela Universidade Federal do Estado do Rio de Janeiro. Professor de História das Redes Municipais de Educação de Gravataí/RS e Sapucaia do Sul/RS. E-mail: wolf_ismael@yahoo.co.uk
} 


\section{Introdução $o^{2}$}

Quando os romanos iniciaram a conquista da Britânia (após 43 d.C.), aquela ilha não tinha uma configuração interna coesa, mas uma série de povos, tribos e confederações. É muito provável que a maioria dos bretões tivesse costumes em comum, mas naquele universo geográfico/cultural havia diversas ramificações com estruturas religiosas e divindades próprias. Ao Norte no território do que, hoje, conhecemos como Inglaterra, estavam os brigantes, ${ }^{3}$ um povo numeroso, conforme descrito por Tácito (De Vita Iulii Agricolae 17), e que com o tempo se tornou cliente dos romanos (Henig, 2003, p. 28). O núcleo territorial brigante estava concentrado basicamente em torno da atual Yorkshire e suas adjacências, mas é provável que sua influência se estendesse para além disso.

Os brigantes, assim como os demais povos bretões, tinham suas peculiaridades religiosas e divindades locais. Nesse sentido, é sabido que adoravam uma divindade chamada Brigantia, provavelmente advinda de experiências e cultos religiosos regionais. O próprio nome da divindade indica esse tipo de relação. ${ }^{4}$ É importante destacar que não temos nenhuma evidência arqueológica que confirme o culto desta divindade antes da chegada dos romanos. Alguns altares, inscrições e raras imagens de Brigantia foram identificados, ${ }^{5}$ mas todas as evidências são do período romano. Esses dados nos mostram que os brigantes até então não tinham o costume de representar suas divindades em imagens antropomórficas. Também é possível que qualquer tipo de representação visual da divindade fosse feito em algum tipo de material menos duradouro e, assim, tenha se perdido. No entanto, essa hipótese carece de bases que a sustentem e, portanto, não iremos discuti-la.

\footnotetext{
${ }^{2}$ Este trabalho é fruto de minha pesquisa no Núcleo de Estudos e Referências da Antiguidade e do Medievo da Universidade Federal do Estado do Rio de Janeiro (NERO-UNIRIO), tendo sido adaptado de meu Trabalho de Conclusão de Curso, finalizado em 2019, sob orientação da Profa. Dra. Claudia Beltrão, a qual aproveito para agradecer a gentileza de sempre, bem como por sua orientação.

${ }^{3}$ Um trabalho fundamental para compreender os brigantes é o de Hartley \& Fitts (1988).

${ }^{4}$ Em termos etimológicos, "Brigantia" e "brigantes" compartilham da mesma raiz "céltica". Visto que "brig" aparentemente tem sido definido pelos estudiosos como "alto", é possível que a raiz dessa palavra esteja identificando o território ocupado pelos brigantes como "elevado" e "montanhoso", ou que essa palavra esteja indicando algum tipo de "nobreza" (Jolliffe, 1941, p. 36).

${ }_{5}^{5}$ Esta informação também é confirmada por McGrath (2015).
} 
A arqueologia identificou apenas duas representações figurativas que consensualmente são identificadas como sendo de Brigantia. ${ }^{6}$ A primeira foi encontrada em 1731, nas proximidades do antigo forte romano de Blatobulgium, um posto avançado (Cunliffe, 2013, p. 405) na atual cidade de Birrens, pertencente ao território da Escócia. ${ }^{7}$ A segunda imagem foi encontrada mais recentemente, no ano de 2014, nas adjacências do forte romano de Arbeia, na atual South Shields, na Inglaterra. ${ }^{8}$ No entanto, neste segundo caso, foi encontrada apenas a cabeça da estatueta. ${ }^{9}$ Ambas as imagens são datadas como sendo do período de ocupação romana.

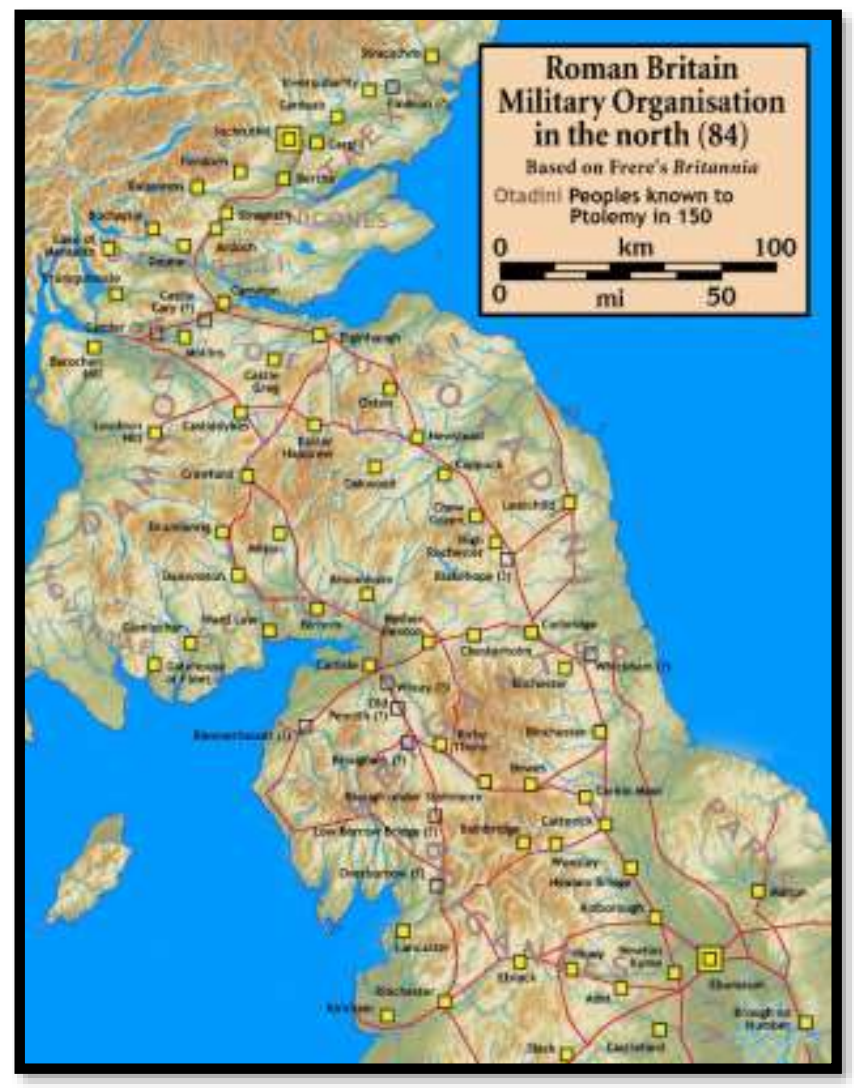

Mapa 1 - Organização militar no norte da Britânia romana.

Fonte: <https://upload.wikimedia.org/wikipedia/commons/1/1b/Roman.Britain.north.84.jpg>

\footnotetext{
${ }^{6}$ Estamos falando aqui de Brigantia nesse contexto geográfico e temporal específico, e não levamos em conta outras possibilidades de divindades posteriores que podem ter uma mesma raiz ou influência como, por exemplo, Brígida, Brigid e Brigitte. Uma boa referência de leitura sobre possíveis derivações dessa divindade é a obra de Wright (2011).

${ }^{7}$ Ver Mapa 1 para maiores informações sobre a localização deste sítio.

${ }^{8}$ Disponível em: <http://www.hadrianswallquest.co.uk/projects/excavation-arbeia-south-shields>. Acesso: 13 jun. 2018.

9 Disponível em: <http://www.dailymail.co.uk/sciencetech/article-2784990/Face-Roman-goddessunearthed-time-1-800-years-Finely-carved-stone-head-depicts-ancient-idol-Brigantia.html>. Acesso: em 13 jun. 2018.

Disponível em: <http://www.hadrianswallquest.co.uk/news/northern-goddess-discovered>. Acesso em: 13 jun. 2019.
} 
Brigantia, em seu caráter de divindade regional, teria sido adotada também pelos romanos. Da mesma maneira que Sulis fora "romanizada"10 no Sul, também Brigantia teria sido "romanizada" no Norte da Britânia, como divindade regional da Província (Henig, 2005, p. 70).

Alguns estudos mais antigos, como os de Nora Jolliffe (1941), defenderam que todas as inscrições datáveis do culto de Brigantia pertenceriam ao período dos reinados de Severo e Caracala. Todavia, pesquisas mais recentes apontam para outras direções, considerando que a imagem de Dea Brigantia de Birrens ${ }^{11}$ teria sido erigida no século II d.C. ${ }^{12}$ Como este é o principal documento que vamos trabalhar neste artigo, é imprescindível levarmos em consideração essa informação, para que se possa fazer uma interpretação no contexto das ideias e da história desse período (Henig, 2005, p. 200203).

Ressaltamos que o tema deste artigo diz respeito não apenas aos estudos sobre a Britânia, mas também sobre possibilidades de conexões entre essa região e outras regiões do Império Romano. As legiões romanas se deslocavam no Império, populações indígenas também faziam deslocamentos (individual ou coletivamente) e, assim, havia um grande fluxo de pessoas se deslocando entre diferentes localidades. Outro ponto importante a considerar é o fato dessa imagem de Brigantia de Birrens ter sido descoberta em uma região de fronteira, também conhecida como limes (Mendes, 2006, p. 41), além do Muro de Adriano. Como fronteira, entendemos algo que vai além de uma simples linha que divide um território de outro. Podemos compreender uma fronteira como um lugar de negociação, onde "diferentes" se colocam frente a frente (Guarinello, 2010, p. 120). Obviamente, existe a possibilidade de tratarmos as fronteiras e limites de cada um, ou de cada ser tomado individualmente, mas aqui se entende a ideia de fronteira como um espaço entre uma comunidade e outra. São fronteiras "intercomunitárias", espaços de trocas, de disputas, de conflitos, de passagens, de acordos, etc (Guarinello, 2010, p. 121122).

No Império Romano, as fronteiras territoriais tinham suas variações de região para região. As características de cada período e espaço geográfico, de certa forma, impunham

\footnotetext{
${ }^{10}$ Conceito cunhado por Theodor Mommsen no século XIX. No entanto, ao longo dos anos, vem sendo problematizado. Como veremos mais adiante, a perspectiva que adotamos neste trabalho nada tem a ver com aculturação.

${ }^{11}$ Disponível em: 〈http://nms.scran.ac.uk/database/record.php?usi=000-100-037-663-C〉. Acesso em: 31 mai. 2019.

${ }^{12}$ Disponível em: <https://romaninscriptionsofbritain.org/inscriptions/2091>. Acesso em: 31 mai. 2019. 
condições para como isso se daria. Pode-se dizer que, em geral, as zonas de fronteira no Império Romano eram espaços onde se concentrava um grande número de soldados. Isso não é à toa, já que Roma expandiu seu território em muitas ocasiões, ou na maior parte delas, através de ações militares. O próprio termo conquista implica em tomar para si algo que antes não estava sob seus domínios (Hingley, 2005, p. 94). Imagina-se então que o Império Romano precisava de soldados para guarnecer os lugares que foram conquistados, estabelecendo limites contra possíveis invasores, ou seja, as zonas de fronteira. A atuação dos comerciantes nesses espaços também deve ser levada em conta, já que o comércio se constituía como um fator importante de relacionamento e interação entre comunidades de diferentes lados de uma fronteira (Hingley, 2005, p. 107).

As fronteiras tinham a "tarefa de estabelecer uma vantagem de comunicação sobre seus oponentes" (Woolf, 2012, p. 208). Eram formadas por uma série de bases que, interligadas, compunham uma rede. A Muralha de Adriano, construída para dividir os limites do Império protegendo-o de invasores "bárbaros", no caso os Caledônios, estava inserida nesse contexto. Além de impressionar pela extensão, um olhar apurado nos mostra que ela servia como referência para o Império Romano e para quem estava fora dele. Havia bases militares romanas dos dois lados da Muralha de Adriano. Obviamente, quem estava além dos limites, no lado externo da Muralha, corria maiores riscos ${ }^{13}$. Além de sua função militar, ela provavelmente tinha uma função política, em vista de sua grande extensão. Era, em suma, algo grandioso que provavelmente deve ter orgulhado o Imperador Adriano e lhe conferido prestígio. Os bretões, que já habitavam aquelas terras, indubitavelmente também foram impactados. Primeiramente de forma visual e simbólica, mas que também influenciou o ir e vir daqueles que costumeiramente cruzavam aquela região. O local onde foi encontrada a imagem de Dea Brigantia, objeto central neste trabalho, ou seja, o forte romano de Blatobulgium (Birrens), é um exemplo claro de materialização das atividades militares do Império Romano em regiões de fronteira.

Nesse sentido, algumas perguntas importantes se colocam: podemos perceber indícios de interações culturais nessa imagem encontrada em uma região fronteiriça do Império? Qual seria a função dessa imagem no contexto em que foi construída?

Precisamos levar em consideração que o Império Romano assume características diferentes dependendo do lugar, do período e das situações específicas nas quais se encontra. No entanto, uma das suas principais características é a conquista cultural,

\footnotetext{
${ }^{13}$ Exposição maior ao inimigo. Nessa situação a própria vida estava constantemente em jogo.
} 
fazendo com que os povos das províncias adotem costumes tipicamente romanos - uma tática exposta por alguns escritores romanos, como Tácito (De Vita Iulii Agricolae 21), e algo que não acontece necessariamente sem algum tipo de resistência indígena. Pelo contrário, essas resistências são complexas (Webster, 1997, p. 167), podendo ocorrer de formas abertas ou veladas. Porém, é importante observar que o termo "romano" adquiriu uma conotação mais ampla no período imperial. Já não dizia respeito apenas aos nascidos em Roma, mas aos cidadãos de todas as partes do Império. Havia todo tipo de contrastes culturais entre eles. Segundo Woolf:

Contrastes entre capital e províncias, Leste e Oeste, pobre e rico, cidade e interior são por si próprias características da cultura imperial romana. Romanização deve ter sido o processo através do qual os habitantes se tornavam e se identificavam como romanos, mas havia mais de um tipo de romano e os estudos da cultura provincial devem considerar a diversidade cultural, assim como a unidade do Império. (Woolf, 1998, p. 7; tradução nossa)

Assim, adotamos a perspectiva teórica apresentada por Woolf. A perspectiva de um Império extremamente diverso culturalmente, não homogêneo, com variedades de relações possíveis. Nesse sentido, nosso uso de romanização não implica em um conceito estanque, ou um processo homogêneo. Da mesma forma, não devemos compreender os processos de conquistas culturais romanas como meramente unilaterais, mas como bilaterais $^{14}$ e interativos ${ }^{15}$, nos quais diferentes elementos interagem com formas e forças distintas dependendo de cada situação específica. À medida que o Império avança, "novas culturas" vão sendo forjadas (Woolf, 1997, p. 341). Assim, as culturas indígenas e romanas foram sendo transformadas, ressignificadas e recriadas diante do contato com os elementos estrangeiros, e em cada localidade é muito provável que isso ocorresse de maneiras diversas. Neste sentido, podemos dizer que a abordagem teórica deste trabalho se enquadra no que conhecemos como estudos pós-coloniais.

\section{Contextualização}

\footnotetext{
${ }^{14}$ Ou multilaterais, quando envolvem vários elementos.

15 Lembrando que essas interações em muitos casos ocorriam de maneira forçada. Da mesma forma, os indivíduos tinham condições distintas nesses processos. Enquanto alguns puderam se beneficiar, outros ficaram majoritariamente com o ônus dessas relações. As interações normalmente ocorrem com desequilíbrio de forças.
} 
Sobre o sítio arqueológico de Birrens, onde foi encontrada a imagem que analisamos neste trabalho, sabemos que, ao longo dos anos, ele passou por uma série de escavações. Temos notícias de algumas muito bem documentadas como, por exemplo, as que ocorreram em 1895, 1936-1937, 1962-1967, 2011, 2012 e 2013. ${ }^{16}$ Dentre os trabalhos sobre o sítio de Birrens, provavelmente o mais aprofundado e destacado é o livro de Robertson, intitulado "Birrens" (Blatobulgium), o qual apresenta detalhes sobre as escavações ${ }^{17}$ e um catálogo de evidências encontradas naquele sítio.

Compreendendo então que houve uma série de escavações em Birrens, em qual momento, onde e por quem foi encontrada a imagem de Dea Brigantia? Segundo relatos, ela teria sido encontrada por volta de 1731 por Sir John Clerk (Christison, 1896, p. 84), $2^{\circ}$ Baronete, político e antiquário escocês (GRAY, 1892). Foi mantida na Pennicuik House, Mid-Lothian, de 1731 a 1857, apresentada por Sir George Clerk, em 1857, à Society of Antiquaries of Scotland, e posteriormente transferida para o National Museum of Scotland, em Edimburgo (Christison, 1896, p. 133).

Ainda que saibamos que Sir John Clerk foi um antiquário bastante envolvido com a descoberta e preservação de artefatos arqueológicos, mesmo que forneça informações importantes sua contextualização sobre o descobrimento da imagem de Brigantia não é muito precisa. Segundo seus relatos, ela teria sido encontrada por ele em um edifício, que acreditava ser um santuário ou templo dedicado também ao deus Mercúrio, do lado de fora das antigas fortificações romanas, trazendo algumas informações confusas sobre o local exato do achado, bem como sobre as reais condições nas quais estava a edificação onde a imagem fora encontrada (Chistison, 1896, p. 84). Em suma, Clerk não forneceu maiores detalhes que pudessem contribuir para uma maior exatidão contextual. Atualmente, a obra continua fazendo parte do acervo do National Museum of Scotland ${ }^{18}$.

\footnotetext{
${ }^{16}$ Entre os envolvidos nessas escavações estiveram a Society of Antiquaries of Scotland, voluntários do Discovering Dumfries and Galloway's Past Project e algumas universidades escocesas como, por exemplo, a University of Glasgow.

${ }^{17}$ Os relatórios de escavações de Christison (1896) e Birley (1937) também são bastante importantes para compreendermos os resultados das escavações realizadas entre o final do séc. XIX e a primeira metade do séc. XX. Informações sobre as escavações mais recentes estão disponíveis em:

<https://canmore.org.uk/event/920878>. $\quad$ Acesso $\quad$ em: $\quad 12 \quad$ jun. 2019 $<$ https://canmore.org.uk/event/992802>. $\quad$ Acesso $\quad$ em: 12 jun. 2019. <https://canmore.org.uk/event/993784>. Acesso em: 12 jun. 2019.

${ }^{18}$ Cf. X.FV 5

Disponível em: <https://www.nms.ac.uk/explore-our-collections/collection-search-results/sculpturefigure/141383>. Acesso em: 21 ago. 2020.
} 
Mare Nostrum, ano 2021, v. 12, n. 1 .

\section{Sobre a metodologia utilizada}

Sabendo o contexto em que a Dea Brigantia de Birrens foi encontrada, tratemos de analisá-la. A imagem foi feita em arenito amarelo (buff sandstone), um material facilmente disponível na Britânia e encontrado em centenas de inscrições, altares e outros achados arqueológicos naquela região. Em termos de dimensões, o objeto mede $93 \mathrm{~cm} \mathrm{x}$ $27 \mathrm{~cm} \mathrm{x} 47 \mathrm{~cm}$.

Partindo destas informações, analisaremos o objeto em etapas distintas. Primeiramente, destacaremos os elementos da imagem (iconografia) e posteriormente aprofundaremos a análise desses elementos (iconologia), com base em alguns componentes do método de análise de imagens de Erwin Panofsky (2009). Vale lembrar que esse método, também conhecido como iconológico, é bastante difundido e valorizado por historiadores da arte, sendo a iconografia a sua parte descritiva e a iconologia a sua parte interpretativa. Devemos compreender que a imagem de Brigantia é um objeto religioso, ou seja, é a imagem esculpida de uma divindade. E ainda que alguém possa alegar que sua função principal não seja artística, é inegável que o componente artístico não pode ser descolado da composição. Dessa forma, o método de Panofsky foi escolhido por propiciar uma boa ferramenta para a compreensão dos significados, visto que o objeto examinado apresenta uma série de elementos que podem e devem ser analisados de forma individual, conjunta e contextual, método que tem sido revalorizado no debate internacional (Lorenz, 2016). Faremos também uma análise da inscrição que consta na obra, compreendendo que esta também é parte importante da composição em sua totalidade. Seguindo esta linha metodológica, iniciaremos destacando os elementos da imagem, faremos uma breve análise de cada um deles e nos aprofundaremos em reflexões interpretativas. 


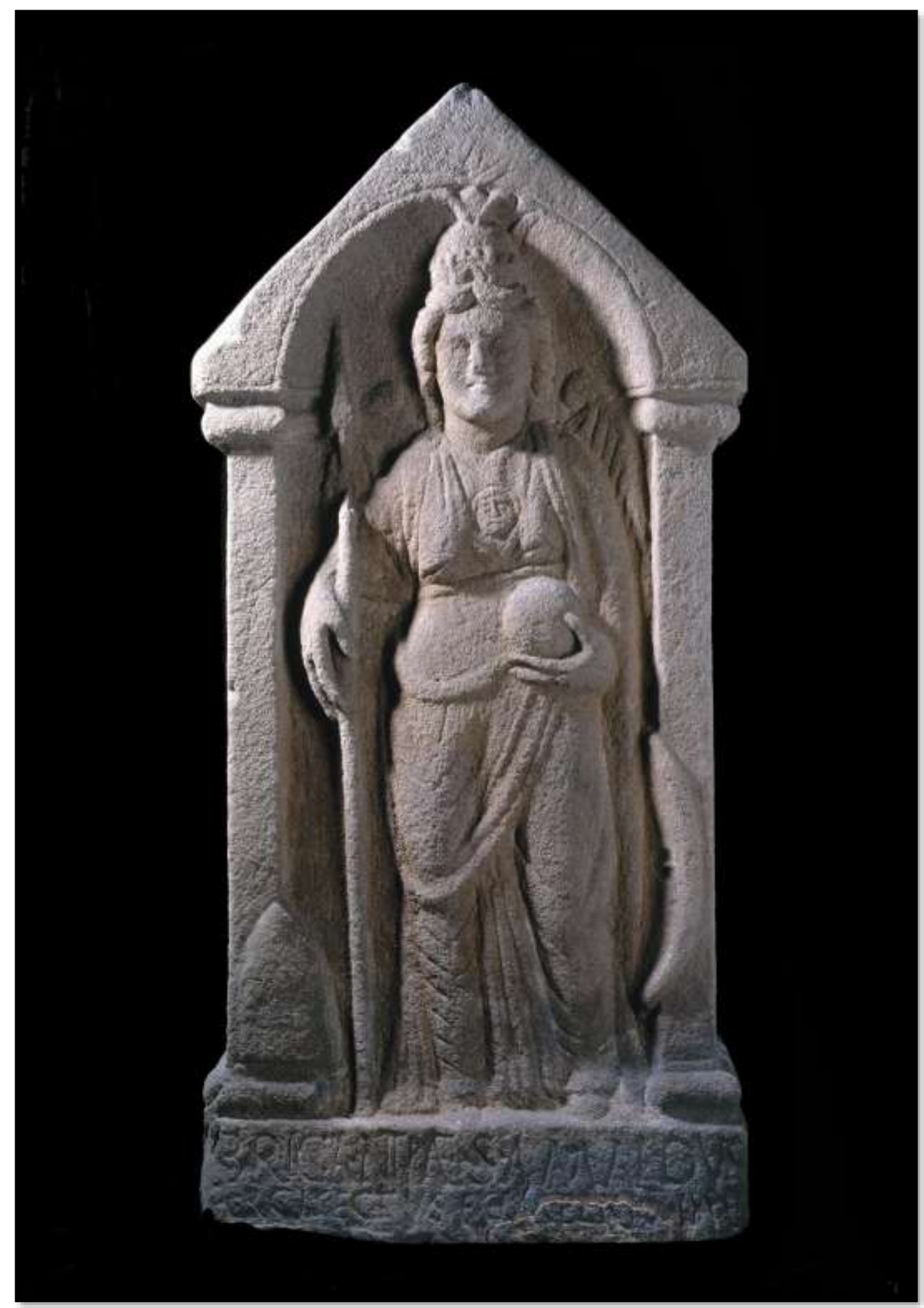

Figura 1. Dea Brigantia de Birrens.

Fonte: https://www.nms.ac.uk/explore-our-collections/collection-searchresults/sculpture-figure/141383 


\section{Identificando e analisando os elementos da imagem}

Uma observação inicial nos permite identificar na figura os seguintes elementos:

Elemento 1: Trata-se de uma figura feminina com asas;

Elemento 2: Ela veste um traje/manto que cobre a maior parte de seu corpo;

Elemento 3: Ela tem sobre sua cabeça uma coroa mural;

Elemento 4: Ela segura um globo em sua mão esquerda;

Elemento 5: Ela segura uma lança em sua mão direita;

Elemento 6: Ao seu lado esquerdo, próximo à sua perna esquerda, podemos observar um escudo;

Elemento 7: Ao lado da lança é possível observar um objeto anicônico (ônfalo);

Elemento 8: Sobre seu peito, ela tem uma medalha de cabeça de górgona.

Aparentemente todos estes elementos se apresentam em um mesmo plano, já que a composição parece salientar o conjunto de elementos, sem que algum seja deixado em um segundo plano. No entanto, podemos ressaltar que o escudo e a pedra anicônica são os únicos elementos da imagem que aparecem ao lado, não estando juntos ao corpo de Brigantia. A técnica utilizada para a composição da escultura cria uma imagem com uma certa aspereza, não parecendo ter havido uma preocupação com o polimento.

Analisando o Elemento 1, fica claro nessa imagem que Brigantia aparece em forma de Minerva (Green, 1996, p. 197). Minerva (ou Atena) foi costumeiramente representada na Antiguidade com o traje longo, o escudo, uma lança e com uma medalha de cabeça de górgona sobre seu peito. Não aparece necessariamente sempre com todos estes elementos, mas isso pode ser observado em boa parte das estátuas dessa divindade. Em Roma, Minerva foi tida como deusa da sabedoria, da medicina, do comércio, do artesanato, da poesia, das artes em geral e da guerra. Minerva era bastante importante no panteão romano, sendo associada à vitória, conforme ilustrado pela dedicação de Pompeu em um templo dedicado a essa divindade após alguns de seus triunfos militares no Leste. ${ }^{19}$ Ainda sobre o Elemento 1, podemos destacar que a imagem de Brigantia também aparece alada como uma Victoria (Henig, 2005, pp. 200-203). Normalmente, as representações antigas da deusa Vitória (Nike, para os gregos) são de uma figura feminina com asas. Essa divindade seria a personificação do ideal de vitória, e imagens dela foram construídas para comemorar triunfos militares. ${ }^{20}$ Como vimos anteriormente, Minerva havia sido

\footnotetext{
${ }^{19}$ Disponível em: <https://www.ancient.eu/Minerva/>. Acesso em: 02 jun. 2019.

${ }^{20}$ Disponível em: <https://www.ancient.eu/nike/>. Acesso em 02 jun. 2019. 
associada por Pompeu à vitória. Dessa maneira, podemos supor que uma representação que mesclasse características de uma Minerva com uma Vitória fosse algo perfeitamente aceitável e compreensível na Antiguidade romana.

No que diz respeito ao Elemento 2, ou seja, ao traje com o qual Brigantia aparece vestida, este está em perfeito acordo com as vestimentas de Minerva. Um traje longo, dando a impressão de ser um tecido fino, uma vestimenta que possivelmente seria digna das elites romanas, garantindo-lhe um ar de sofisticação e superioridade. Um traje que seria considerado digno para um romano e distante para um bárbaro.

O Elemento 3, a coroa mural que está sobre sua cabeça, é um elemento típico das representações de divindades tutelares de alguma cidade ou região, indicando seu caráter protetor. A coroa mural (corona muralis) ${ }^{21}$ na cultura helenística identificava também a deusa Tyché, a qual era conhecida pelos romanos como Fortuna. É possível que, ao produzir a imagem, o escultor tenha pensado em Brigantia como uma protetora da região, ou tenha sido orientado por outra pessoa nesse sentido. $\mathrm{O}$ fato de a imagem de Brigantia ter sido encontrada bem ao Norte da província da Britânia, longe de Eboracum e dos principais centros brigantes, pode indicar que seu culto havia se espalhado pelo Norte da província (Jolliffe, 1941, p. 50).

No que diz respeito ao Elemento 4, o globo que a figura de Brigantia segura em sua mão esquerda seria um símbolo de que ela governa o mundo, o que sugere o poder imperial (Jolliffe, 1941). Pode-se sugerir também alguma relação com a figura mitológica de Atlas, o Titã que fora sentenciado por Zeus a carregar o peso do céu. No entanto, devemos lembrar que, enquanto a estátua do Atlas Farnésio carrega a esfera celeste sobre seus ombros, sugerindo algum esforço surreal e intenso, a estatueta de Brigantia de Birrens parece segurar de forma tranquila o globo que está em sua mão esquerda, sem que isso sugira algo penoso. Assim, parece mais coerente pensarmos o Elemento 4 como uma sugestão de poder.

No que tange aos Elementos 5 (lança) e 6 (escudo), podemos dizer que conferem à Brigantia de Birrens um caráter bélico, também presente nas figuras de Minerva: a lança como arma de ataque e o escudo como arma de defesa. Estes são dois elementos importantes e que são facilmente associados a um comportamento guerreiro. Nas legiões romanas era comum o uso do pilum e do scutum. Em se tratando de uma região com conflitos militares é muito provável que os dois elementos fossem familiares aos olhos

\footnotetext{
${ }^{21}$ A corona muralis é citada, por exemplo, por Aulo Gélio em Noites Áticas 5.6.
} 
daqueles que ali habitassem. Devemos lembrar que o local onde a imagem foi encontrada estava nas proximidades de um forte romano, ou seja, um local frequentado por homens de guerra. Outro ponto importante é o fato de estar na fronteira entre o território ocupado pelos romanos e aquele ocupado pelos caledônios/pictos, povo que representava um desafio às ambições romanas de controlar toda a Britânia. Assim, construir uma imagem de uma divindade com características militares parece-nos algo sensato.

Já o Elemento 7, a pedra anicônica, identificada como um ônfalo (do grego omphalós), é um elemento conhecido no mundo Mediterrâneo desde a Idade do Bronze (Crooks, 2012, p. 25-44). O termo omphalós significa umbigo. Ele foi citado por Pausânias em sua narrativa sobre Delfos: “O que é chamado Ônfalo（Umbigo） pelos habitantes de Delfos é feito de mármore branco, e é dito pelos habitantes de Delfos como o centro de toda a terra" (Graeciae Descriptio 10:16.3). ${ }^{22}$ Quando observamos outros ônfalos, como o de Delfos, notamos que há similaridade com o objeto figurado na imagem de Brigantia de Birrens. Trata-se de uma pedra que, para helênicos e romanos, seria "o centro da ordem cosmológica, o ponto em que as forças divinas irrompem no mundo" (Moulakis, 2000, p. 30), ou seja, o "umbigo da Terra", de acordo com o mito de que Zeus teria enviado duas águias para lados opostos e elas teriam se encontrado em Delfos, o centro do mundo. ${ }^{23}$ Esse umbigo era representado então por uma pedra, que funcionaria como uma espécie de ponto de contato entre os homens e os deuses. Este mito, assim como o elemento ônfalo, era conhecido também no mundo romano. Assim, não é estranha a sua presença na imagem de Brigantia de Birrens, provavelmente estabelecendo o local onde foi colocada como um ponto de contato, ou "lugar de comunicação" (Eliade, 2016, p. 188-189), entre os homens e aquela divindade. ${ }^{24}$

Por fim, tratemos do Elemento 8, o camafeu (cammaeus) com a cabeça de górgona, também conhecido como gorgonião. Trata-se de uma espécie de amuleto apotropaico. De acordo com um mito grego, Perseu derrotou a Medusa ${ }^{25}$ e arrancou-lhe a cabeça. Ela lhe teria sido útil posteriormente, pois Perseu a teria usado para petrificar o Titã Atlas (Wilk, 2000, p. 17-29). Partindo deste mito, podemos entender que a cabeça de górgona parece ter um caráter mágico e de ataque ao inimigo. Ela foi frequentemente

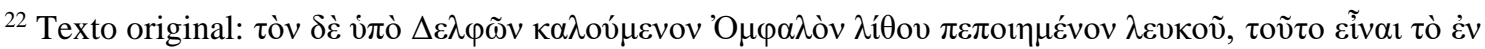

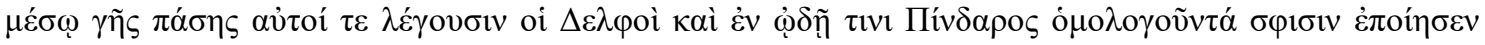
(Graeciae Descriptio 10:16.3.)

${ }^{23}$ Disponível em: <http://odysseus.culture.gr/h/4/eh430.jsp?obj_id=4687>. Acesso 12 Jun. 2019.

${ }^{24}$ Conforme aventado por Eliade (2016), o omphalós poderia ser reconhecido como um lugar de conexão entre três domínios: dos vivos, dos mortos e dos deuses.

${ }^{25}$ Provavelmente a mais famosa e retratada das Górgonas.
} 
utilizada na Antiguidade, sendo retratada, por exemplo, em moedas, edifícios públicos, templos e escudos (GIMBUTAS, 1999, p. 26). O gorgonião aparece também com frequência em imagens de Atena colocado sobre seu peito, assim como está também sobre o peito da Brigantia de Birrens e de estátuas de Minerva, em uma clara alusão ao controle sobre os inimigos, petrificando-os e paralisando-os por completo.

\section{Analisando a inscrição}

Após observarmos os elementos presentes na imagem, trataremos da epígrafe de Brigantia de Birrens. Devemos lembrar de que elementos visuais e textuais fazem parte da mesma composição. ${ }^{26}$ Assim, ambos os elementos são igualmente importantes para que tenhamos uma compreensão mais aprofundada desse "documento cultural" (D’Encarnação, 2010, p. 17). Como podemos observar na imagem abaixo, a inscrição está localizada exatamente na parte inferior da peça, logo abaixo da figura de Brigantia.

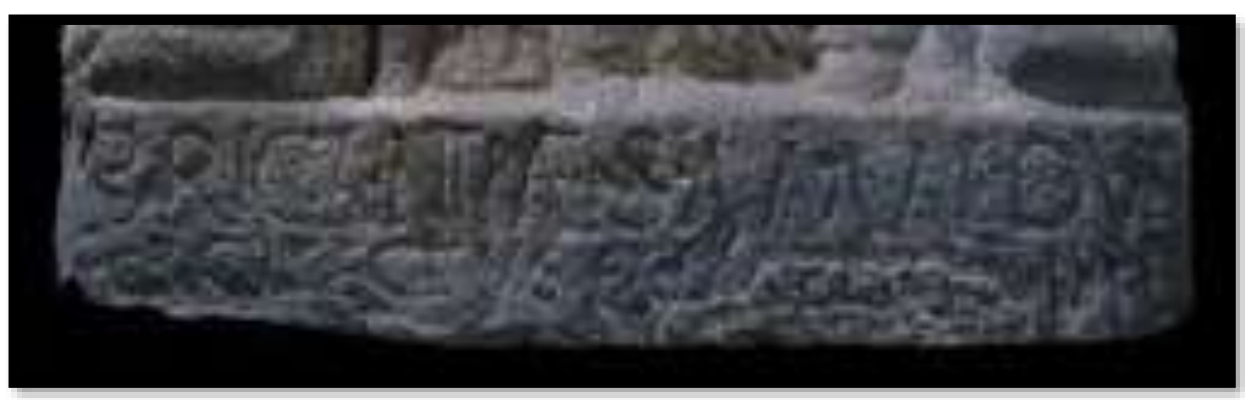

Figura 2. Inscrição da estatueta de Brigantia de Birrens.

Embora a inscrição tenha perdido um pouco de sua nitidez, assim como todo o restante da peça, ainda é possível observar a maior parte do que está escrito. Vejamos a Figura 11:

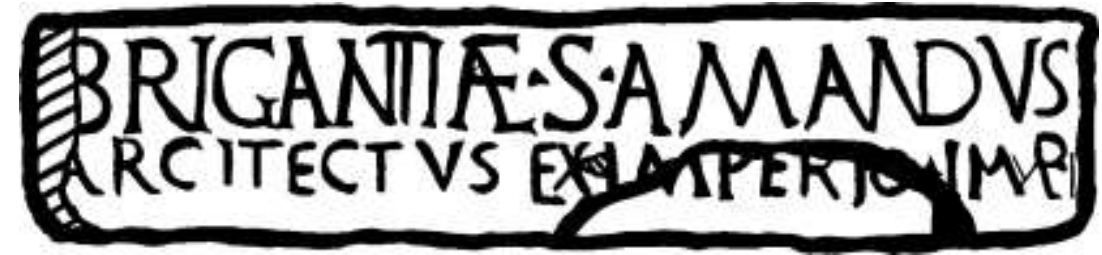

Figura 3. Reprodução da epígrafe de Brigantia de Birrens. ${ }^{27}$

Fonte: 〈https://romaninscriptionsofbritain.org/images/RIB002091.png>

\footnotetext{
26 Não encontramos nenhum autor que sustente a hipótese de que a epígrafe tenha sido inserida posteriormente. Dessa forma, não vemos motivos para sugerir uma discussão nesse sentido.

${ }^{27}$ Cf. RIB 2091.
} 
Mare Nostrum, ano 2021, v. 12, n. 1 .

$\mathrm{Na}$ imagem acima podemos ver o texto de forma mais clara. ${ }^{28}$ De acordo com a página do projeto Roman Inscriptions of Britain, podemos transcrever esta epígrafe das seguintes maneiras: ${ }^{29}$

*Edição: Brigantiae s (acrum) Amandus arco (h) itectus ex imperio imp (eratum) (fecit)

*Diplomático: BRIGANTIAE S AMANDVS ARCITECTVS EX IMPERIO IMP (FECIT)

*Edição contínua: Brigantiae s (acrum) Amandus | arco (h) itectus ex imperio imp (eratum) (fecit)

Levando em consideração esta convenção, o texto pode ser traduzido como: "Consagrado à Brigantia: Amandus, o engenheiro, cumpriu a ordem de comando." Cientes disso podemos estabelecer algumas perguntas iniciais: Quem seria Amandus? E o que significaria "cumpriu a ordem de comando"?

Não há consenso sobre quem teria sido Amandus. No entanto, algumas possibilidades foram levantadas. Miller (1937, p. 208-209) levantou a hipótese de que Amandus pode ter sido Valerius Mandus, presente em uma inscrição ${ }^{30}$ datada de 209 d.C. ${ }^{31}$ encontrada em Iversheim, uma área no norte de Bad Münstereifel, no distrito de Euskirchen, Estado da Renânia do Norte-Vestfália, na atual Alemanha. Sabemos que a região de Iversheim de fato recebeu trabalhos de engenharia romana, já que a presença dos romanos na região está bem evidenciada, por exemplo, através de um forno de cal romano, provavelmente construído em meados do ano 100 d.C. ${ }^{32}$ Dessa forma, de acordo com Miller, Valerius Amandus pode ter sido algum legionário que trabalhou em mais de

\footnotetext{
${ }^{28}$ Reproduzido por R.P.W., 1946.

${ }^{29}$ Disponível em: <https://romaninscriptionsofbritain.org/inscriptions/2091>. Acesso em: 08 jun. 2019.

$30 \quad$ Cf. CIL 2459 Disponível em: <https://archive.org/details/inscriptioneslat03dessuoft/page/clxxviii>. Acesso em 08 jun. 2019.

${ }^{31}$ Disponível em: <https://romaninscriptionsofbritain.org/inscriptions/2091>. Acesso em 08 jun. 2019.

32 Disponível em: <https://www.nordeifel-tourismus.de/sehenswertes-kultur/archaeologischedenkmaeler/roemische-kalkbrennerei-iversheim/>. Acesso em: 08 jun. 2019.
} 
um lugar, realizando trabalhos de engenharia na Germânia e depois na Britânia. A função de engenheiro (architectus) era um grau legionário. ${ }^{33}$

A engenharia romana era parte muito importante da engrenagem do Império. Onde chegavam, os romanos desenvolviam seus mais variados trabalhos de engenharia: castra, fortes, aquedutos e banhos, por exemplo, eram algumas destas obras de engenharia desenvolvidas e levadas aos mais diferentes lugares do Império. Essas obras, de um modo ou de outro, constituíam-se como uma espécie de "lugares de memória"34 (Nora, 2008) para os romanos, fossem antigos ou novos cidadãos, contribuindo para construir e perpetuar uma "memória coletiva" (Halbwachs, 1990) dentro do Império. O tratado de engenheira romana do qual temos notícia chama-se De Architectura ${ }^{35}$ e foi escrito no séc. I a.C., por Marcos Vitrúvio Polião. É uma obra composta por dez volumes ${ }^{36}$, na qual Vitrúvio discorre sobre diferentes aspectos que fazem parte da engenharia/arquitetura. Pode-se dizer que esta obra de Vitrúvio estabeleceu as bases não apenas para a engenharia romana, mas também influenciou diferentes gerações de construtores. No que tange ao termo arquitectus é necessário deixar claro que não se trata exatamente do que atualmente chamamos de arquiteto. ${ }^{37}$ Ao que tudo indica, um arquitectus romano poderia ser responsável por diversos tipos de projetos como, por exemplo, edifícios, planejamentos de cidades, fortificações, sistemas hidráulicos, etc. Ele também poderia desenvolver projetos "menores", os quais incluíam relógios, máquinas e equipamentos de artilharia (Rowland, 2014, pp. 413-414).

Ainda que Miller tenha tentado estabelecer uma relação entre o Amandus de Birrens e o Amandus de Iversheim é pouco provável que se trate da mesma pessoa. A possibilidade levantada por Miller apontava para que o Amandus de Birrens tivesse erigido a imagem de Brigantia por volta das primeiras décadas do século III d.C. No entanto, não há evidência material de que Blatobulgium tenha sido ocupada após 180-184 d.C. Como bem apontado por Robertson (1975) e por Keppie (1994), há um hiato de cerca de vinte anos entre o vestígio material mais tardio encontrado em Birrens e a data sugerida para a inscrição de Iversheim. Assim, qualquer tentativa de relacionar o Amandus de

\footnotetext{
${ }^{33}$ Disponível em: <https://romaninscriptionsofbritain.org/inscriptions/2091〉. Acesso em: 08 jun. 2019.

${ }^{34}$ Conceito de Pierre Nora. Aqui o adaptamos para a Antiguidade.

${ }^{35}$ Disponível em: <http://www.gutenberg.org/ebooks/20239>. Acesso em: 08 jun. 2019.

36 Disponível em: <http://penelope.uchicago.edu/Thayer/E/Roman/Texts/Vitruvius/home.html>. Acesso em: 08 jun. 2019.

${ }^{37}$ Esse é o motivo pelo qual anteriormente traduzimos arquitectus como "engenheiro".
} 
Birrens com o Amandus de Iversheim deve ser descartada, pelo menos até que alguma evidência material posterior possa ser apresentada - o que, até o momento, não é o caso.

Como já dissemos, architectus era um grau legionário, o que nos leva a crer que provavelmente cada legião contasse com um em suas formações. Assim, é provável que Amandus fosse um architectus que fizesse parte de uma das legiões estacionadas no Norte da Britânia, provavelmente membro da Legio VI Victrix, legião que se estabeleceu predominantemente no centro urbano de Eboracum (York) (Ottaway, 2013, p. 11). É fácil imaginar os legionários se deslocando em campanhas e missões militares nas áreas mais extremas da Província, nas proximidades das Muralhas de Adriano e de Antonino.

Prossigamos em nossa breve análise epigráfica. De acordo com a inscrição na parte inferior da imagem de Dea Brigantia de Birrens, consta que Amandus "cumpriu ordem de comando", ou seja, lhe foi dada uma ordem para que erigisse uma estatueta consagrada para Brigantia, algo que foi cumprido. Os termos latinos utilizados são "ex imperio". Partindo destes termos, podemos trabalhar com algumas possibilidades interpretativas.

A primeira possibilidade é a de que Amandus poderia ter sido alguém que cumpriu ordem recebida de um superior, provavelmente alguém que havia feito algum voto e necessitava cumpri-lo. Não seria algo incomum que alguém de hierarquia superior solicitasse que outro indivíduo cumprisse uma missão ou um trabalho. Assim, Amandus pode ter sido o mero intermediário que cumpriu ordem de comando vinda de um de seus superiores. A segunda possibilidade é a de que Amandus pode ter cumprido alguma ordem vinda por parte de algum sacerdote, ou mesmo cumprido algum voto realizado por ele mesmo, como forma de pagar algum benefício alcançado. Uma terceira possibilidade seria a de que Amandus poderia ter tido algum tipo de epifania com a própria divindade.

Aqui entendemos a epifania como uma experiência de contato entre seres humanos e divindades. Uma revelação trazida por alguma divindade para um mortal, sendo essas culturalmente mediadas. Em todos os casos mitológicos que envolvem epifanias há sempre um ponto de contato, uma linguagem em comum. Dessa forma, mesmo o mistério das divindades é colocado de forma perceptível. A experiência da epifania permite que o destinatário da mensagem a receba através de códigos de linguagem que lhes sejam compreensíveis (Platt, 2015, p. 493). Uma epifania poderia se dar em uma situação de ritual religioso ou através de um sonho, mas também poderia ocorrer em uma situação extrema, como em meio a uma batalha, no topo de uma montanha, ou em algum lugar inóspito. Junto a isso, devemos entender que no mundo 
greco-romano a epifania era tida como algo que dependeria do arbítrio das divindades (Platt, 2015, p. 494). No que tange à sua função, aceitamos a tese de Platt (2015) de que as epifanias são etiológicas: “A experiência passageira e altamente subjetiva da epifania é convertida pelos indivíduos, através do estabelecimento de honras de culto, em um reconhecimento estável e duradouro do poder da divindade e a presença potencial dentro de um local específico" (p. 495). Dessa forma, é possível dizer que a experiência de uma epifania pode ser rememorada através de algo físico, como uma imagem, inscrição, etc.

Partindo destas definições, seria perfeitamente aceitável a possibilidade de que Amandus tivesse cumprido ordem de comando vinda através de uma epifania. Em resposta à visão, Amandus poderia ter erigido uma imagem de Dea Brigantia, prestando honra à divindade através de sua obediência. Certamente, não é possível sabermos qual dessas possibilidades é a correta. A falta de dados complementares dificulta que a questão possa ser respondida definitivamente. Assim, precisamos manter em aberto essas três possibilidades interpretativas.

Após análise do conjunto figura/inscrição, devemos lembrar que Brigantia fora concebida com atributos de Minerva por seu escultor. A figura é de uma mulher portando um escudo e uma lança, ambas armas de guerra, tanto de defesa como de ataque. Da mesma forma, ela porta uma medalha de cabeça de górgona sobre seu peito como instrumento para paralisar seus inimigos. Por também ter sido retratada como uma divindade tutelar, podemos supor que Amandus podia estar agradecendo por alguma vitória, ou pela conquista de um território. O fato da imagem de Brigantia ser apresentada alada como uma Vitória também converge no sentido de que a imagem pode ter sido oferecida por Amandus como agradecimento por alguma conquista. Por fim, o ônfalo sugere um local de comunicação entre a divindade e os mortais, o que pode passar uma mensagem para o observador de que o local onde estivesse a imagem seria o local de contato.

\section{Possíveis conexões}

Vamos tentar ir um pouco além, buscando encontrar possíveis conexões entre a imagem de Dea Brigantia de Birrens e outras formas de culto/religiosidade no contexto do diverso Império Romano (Garraffoni, 2020, p. 55). Comecemos pela figura. A própria maneira como Brigantia foi figurada remete a outras divindades. Após uma simples observação já podemos perceber que ela foi esculpida como uma Minerva, divindade 
romana parte da Tríade Capitolina (Kaizer, 2007, p. 447). É perceptível que aí já haja uma intermediação cultural. Afinal, uma divindade da Província da Britânia fora retratada como uma divindade romana conhecida em todo o Império. É possível que Brigantia já estivesse sendo interpretada como Minerva pelos romanos, ou ainda que tivesse sido percebida dessa forma durante o momento da possível epifania de Amandus, ou ainda as duas coisas. ${ }^{38}$ De toda forma, há aí um jogo de aproximação cultural entre uma divindade local e uma cultura religiosa romana mais geral. Devemos lembrar que na Britânia também havia o culto à Sulis Minerva (Aquae Sulis), a qual possuía um santuário. Assim, não há dúvidas de que a forma já tradicional de Minerva fosse conhecida na Britânia, sendo relacionada com divindades locais. $\mathrm{O}$ fato de a imagem de Brigantia de Birrens ser alada como uma Vitória, também aponta para o mesmo caminho de interação cultural. Sabemos que a Vitória estava presente no imaginário romano, sendo vista nos monumentos mais diversos. Os demais elementos presentes na imagem também transmitem uma mensagem ao observador. A vestimenta, as armas, a cabeça de górgona e o ônfalo faziam parte do imaginário do mundo romano, assim como os mitos, histórias e lendas que os cercavam. Todo este imaginário cultural/religioso provavelmente era transportado junto com as legiões que se deslocavam pelas diferentes partes do Império. A análise da imagem permite identificar claramente esses traços de interação cultural.

Voltemos à inscrição. Seria possível encontrar algo similar em outras partes do Império? O termo "ex imperio" faz parte de um conjunto de inscrições que pode ser denominado como inscrições de revelação (Offenbarungsinschriften: Stolte, 1986). Ele pode ser encontrado em alguns exemplos fora da Britânia. Vejamos um desses casos:

Matron(is) Gesahen[i]s / M(arcus) Iul(ius) Valentinus / et Iulia Iustin[a] / ex imperio ipsarum l(ibentes) $m(\text { erito })^{39}$

Este é um dos inúmeros casos de inscrições encontradas na Germânia Inferior e, como podemos observar, se trata de uma dedicação às Matronas (Matronae). O culto dessas divindades parece ter sido muito forte naquela Província, o que é evidenciado pela

\footnotetext{
${ }^{38}$ Não devemos descartar a possibilidade de que a população indígena estivesse já à sua maneira esculpindo imagens de Brigantia como forma de adaptação resistente. Esse é um conceito de Stern, reportado por Webster (1997, p. 170). Isso poderia estar influenciando o imaginário religioso romano.

${ }^{39}$ Cf. CIL 13, 7889. Disponível em:

<http://db.edcs.eu/epigr/bilder.php?bild=\$TR_CIL_13_07889_1.jpg;\$TR_CIL_13_07889_2.jpg;\$TR_CI

L_13_07889_3.jpg;\$TR_CIL_13_07889_4.jpg>. Acesso em: 10 jun. 2019.
} 
grande quantidade de inscrições encontradas naquela região (Woolf, 2003, p. 131). Podemos enquadrar nosso exemplo na categoria dedicatórias, e que, neste caso específico, está acompanhada de uma figuração, assim como no caso da Brigantia de Birrens.

Esta inscrição pode ser traduzida como "Para as Matronas Gesachenae! Marcus Iulius Valentinus e Iulia Iustina cumpriram, de bom grado e merecidamente, uma ordem delas". Podemos observar que há uma diferença pequena, mas fundamental, entre o uso do termo ex imperio na inscrição de Dea Brigantia de Birrens e na inscrição das Matronas Gesachenae. Enquanto na inscrição de Dea Brigantia o termo ex imperio está acompanhado de imperatum, na inscrição das Matronas ele vem acompanhado de ipsarum. Isso abre possibilidade para diferentes interpretações. $\mathrm{O}$ termo imperatum carrega consigo um sentido de ordenado, ou comando. Já o termo ipsarum é a forma no genitivo feminino plural do pronome ipse, ou seja, significa "elas mesmas". Dessa maneira, enquanto na inscrição das Matronas Gesachenae há a afirmação de que foi “cumprida ordem" vinda "delas", na inscrição de Dea Brigantia há a afirmação de que Amandus cumpriu uma "ordem de comando". Ao analisarmos outras dedicatórias para Matronas, observamos o constante uso de ex imperio ipsarum. Ao mesmo tempo, não encontramos o uso de ex imperio imperatum. Na verdade, encontramos o uso de ex imperio imperatum apenas na inscrição de Brigantia de Birrens, mesmo após realizarmos buscas em bancos de dados como o Epigraphik-Datenbank Clauss / Slaby (EDCS) ${ }^{40}$.

Após analisarmos essas informações, como podemos encará-las? Em um primeiro momento poderia parecer que qualquer conexão entre Dea Brigantia de Birrens e as Matronas deveria ser descartada. No entanto, devemos lembrar que o uso do termo ex imperio pode ser observado com alta frequência em dedicatórias para as Matronas. Não parece pertinente descartar a possibilidade de que o escultor de Brigantia de Birrens, ou a pessoa que financiou a obra, estivessem familiarizados com esse tipo de dedicatória. Inclusive, sabemos que o culto às Matronas adquiriu certa relevância na Província da Britânia (Green, 2006, p. 213). Assim, é perfeitamente aceitável a hipótese de que haja alguma relação entre a forma da inscrição de Dea Brigantia de Birrens com as inscrições das Matronas. É sabido que na religião ancestral celta o culto a uma divindade feminina, normalmente associada à fertilidade, assim como o culto a divindades femininas triplistas, era comum. E embora houvesse diferença de culto de um lugar para outro, como, por

\footnotetext{
${ }^{40}$ Disponível em: <http://db.edcs.eu/epigr/epi.php?s_sprache=en>. Acesso em: 10 jun. 2019.
} 
exemplo, mudanças de alguns teônimos, o culto a essas divindades femininas era recorrente (Monaghan, 2004, p. XII-XIV). É provável que os bretões já estivessem habituados com o culto a este tipo de divindades antes da chegada dos romanos à ilha. Ainda assim, é lúcido aceitar que a chegada das legiões romanas tenha propagado tais formas de culto, já incorporadas pelo sistema romano. ${ }^{41}$ Mesmo que não haja recorrência de outras inscrições com utilização do termo ex imperio nas inscrições romanas na Britânia, há altares e inscrições de dedicatórias às Matronas. ${ }^{42}$ Isso pode ser o resultado da assimilação de divindades cultuadas pelos bretões, assim como a introdução de formas cultuais vindas de outros locais do Império, como a Germânia Inferior. Não se tratava apenas de "fluxo de informações", mas também de fluxo de algumas formas de organização da “ação ritual” (Woolf, 2016, p. 54). Possibilidades de conexões culturais devem ser consideradas, ainda mais quando lembramos que o Império Romano formava uma grande rede de interações.

\section{Possíveis impactos}

Após a análise da imagem e termos buscando possíveis pontos de conexões culturais, faremos uma reflexão sobre os possíveis impactos da imagem de Brigantia de Birrens sobre a população indígena bretã.

Como sabemos, a imagem de Brigantia de Birrens foi encontrada numa região que atualmente corresponde a uma área no Sul da Escócia e que, naquela época, era habitada por outros povos. Quando pensamos em população indígena precisamos ter em mente os povos que já estavam estabelecidos na Britânia antes da chegada dos romanos na ilha. De acordo com a descrição de Ptolomeu, ${ }^{43}$ o povo que vivia na região da atual Dumfriesshire, onde ficava o forte romano de Blatobulgium, se chamava selgovae e provavelmente era um povo constituído por caçadores, o que é confirmado por Barrow (1989, p. 161-163).

\footnotetext{
${ }^{41}$ A cultura material nos mostra que legiões e cohortes que estiveram na Britânia tinham passagem anterior pelo Vale do Reno, ou seja, uma região que a Arqueologia já demonstrou ser foco de culto para divindades femininas, incluindo as Matronas. Algumas dessas legiões e cohortes certamente estiveram em algum momento em Blatobulgium: Legio XX Valeria Victrix (RIB 2114), Legio VI Victrix (RIB 2112; 2113), Cohors Primae Nervana Germanorum Milliaria Equitata (RIB 2093; 2097) e Cohors Secundae Tungrorum Milliaria Equitata (RIB 2092; 2094; 2100; 2104; 2107; 2108; 2109; 2110; 2115).

${ }^{42}$ Disponível em: <https://romaninscriptionsofbritain.org/>. Acesso em 11 jun. 2019.

${ }^{43}$ Disponível em:

$<$ http://penelope.uchicago.edu/Thayer/E/Gazetteer/Periods/Roman/_Texts/Ptolemy/2/2*.html>. Acesso em: 11 jun. 2019.
} 
Sabe-se também que os selgovae estavam localizados um pouco ao Norte do território dos brigantes, povo que tem seu nome relacionado ao de Dea Brigantia.

Assim como os demais celtas $^{44}$, esses bretões do Norte devem ter sentido um impacto interessante ao se depararem com a imagem de Brigantia de Birrens, dado que os celtas não costumavam conceber suas divindades em forma humana, nem mesmo costumavam esculpi-las ou pintá-las em forma física (Monaghan, 2004, p. XIII). Como já vimos, não há vestígio arqueológico do culto de Brigantia anterior à presença romana na Britânia. No entanto, é possível que Brigantia fosse uma divindade feminina, ainda que não fosse antropomorficamente representada. É importante pensar, ainda que de forma sucinta, a importância das relações de gênero nesse universo romano-céltico. Alguns autores têm defendido que as representações femininas de divindades celtas poderiam sugerir uma espécie de dominação física e psicológica do poder imperial romano sobre os povos indígenas (Webster, 1997, p. 175). No entanto, ainda que essa perspectiva possa ser verossímil em situações específicas parece sensato que não façamos generalizações nesse sentido, ainda mais porque tal afirmação teria que partir da premissa de que, para gerar um impacto negativo sobre os bretões, eles próprios teriam que considerar as divindades femininas como menos poderosas.

Como bem sabemos, a Britânia foi retratada pelos escritores latinos como sendo um lugar onde as mulheres exerciam importantes posições na sociedade. ${ }^{45}$ Some-se a isso o fato de que a imagem de Brigantia de Birrens não aparece ao lado de outra divindade masculina, ou seja, ela foi retratada sozinha, e a dedicatória é exclusiva. $\mathrm{O}$ a que difere, por exemplo, de outros casos conhecidos de divindades indígenas que foram retratadas ao lado de divindades masculinas do panteão romano, sugerindo uma perspectiva de justaposição entre a figura masculina romana civilizada e a mulher indígena bárbara que poderia demonstrar um “desequilíbrio de gênero" (Webster, 1997, p. 171). O fato de Brigantia ser retratada como uma divindade feminina com atributos greco-romanos parece muito mais sugerir algum tipo de síntese e/ou "facilitador" (Webster, 1997, p. 179) para a permanência ou a propagação do culto desta divindade.

A figura de uma divindade local em forma humana esculpida em pedra deve ter causado certa estranheza sobre a população indígena. Existe também a possibilidade de

\footnotetext{
${ }^{44}$ Lembramos que o que aqui chamamos de "celtas" nada mais é do que um conjunto de diferentes povos que possuíam um bom número de elementos culturais em comum. No entanto, não há qualquer evidência que sustente que esses povos se reconhecessem como "celtas".

${ }^{45}$ Podemos ver isso bem representado nas obras de Tácito, onde ele traz exemplos como Cartimandua e Boudica.
} 
que Brigantia fosse vista pela população indígena como um tipo de deusa mãe, ancestral de todo o povo, assim como pode ter ocorrido com outras divindades e outros povos “celtas". Um caso semelhante é o da deusa Danu, a qual empresta seu nome ao Rio Danúbio. Mesmo sendo divindades da terra, essas deusas mães também governavam os rios que regavam os solos, o que lhes conferia um caráter de deusas da fertilidade. Por esse motivo, seus nomes também poderiam ser associados aos rios que compunham o território onde eram cultuadas (Monaghan, 2004, p. XIII-XIV). Pensando em questões territoriais, é possível dizer que a coroa mural utilizada sobre a cabeça de Brigantia de Birrens corrobora a ideia de que ela poderia ser vista como divindade tutelar daquele território.

Sobre seu impacto visual, existe outro fator que devemos considerar. Não bastasse o fato de Brigantia ter sido esculpida em forma humana, ela também foi construída como uma imagem romana, ou seja, com a imagem do povo invasor. Tanto as vestes, como os demais elementos da imagem remetem à cultura greco-romana, o que provavelmente deve ter causado uma estranheza ao observador bretão indígena comum ${ }^{46}$. No entanto, precisamos ter em mente que este impacto pode ter sido diferente dependendo de quem fosse o observador.

Imaginemos qual poderia ter sido o impacto sobre um membro da elite bretã. Mesmo que a imagem de Brigantia esculpida em forma humana lhe causasse alguma estranheza, se ele estivesse alinhado com os interesses de Roma, sendo um novo cidadão romano ou algum rei cliente, é possível que não apenas aceitasse a imagem de Brigantia vestida em um padrão greco-romano, como também poderia compreender os atributos com os quais ela foi representada, identificando nela similaridades com uma Minerva, ou que ela teria sido assimilada ao sistema religioso romano através de algum tipo de interpretatio $^{47}$. Sua imersão na cultura romana lhe possibilitaria acessar os significados intrínsecos de cada elemento da imagem e da composição como um todo. Da mesma forma, membros de uma legião romana ou de uma tropa auxiliar também poderiam realizar a sua interpretação de uma maneira diferente, observando os atributos militares presentes na imagem. Já alguém não alinhado com os interesses de Roma poderia se escandalizar ao perceber que uma divindade local fora cooptada pelos romanos. Nos

\footnotetext{
46 Ao analisarmos a imagem não encontramos referências diretas da divindade autóctone. É apenas a epígrafe que garante essa relação de forma segura.

${ }^{47}$ Forma de interpretação ou tradução pela qual os romanos identificavam divindades oriundas de outras culturas como equivalentes às suas.
} 
escritos de Tácito podemos perceber que as “coisas de Roma” causavam ódio ${ }^{48}$ em alguns (Historiae 3.45).

Outra situação que podemos conjecturar seria o impacto visual dessa imagem em uma zona de fronteira. Como a imagem estava numa zona extremamente militarizada (Hingley, 2005, p. 94) e repleta de conflitos e inseguranças (Hingley, 2010, p. 110), a presença de uma divindade tutelar e com atributos mágicos, como a cabeça de górgona, poderia trazer alguma sensação de proteção para aqueles que estavam estacionados em Blatobulgium e adjacências. De certa forma, o ônfalo presente na estatueta também poderia elevar o local da imagem a um ambiente especial para o contato entre a divindade e aqueles que lhe prestassem culto. Outro fator que poderia gerar impacto visual seria o atributo de Vitória presente na imagem, provavelmente rememorando algum triunfo militar ou conquista de território. $\mathrm{O}$ fato de Brigantia receber uma dedicatória além dos limites do território brigante pode, inclusive, significar que havia uma presença brigante entre os militares, estando eles alinhados e/ou cumprindo ordens do poder romano.

Devemos ter em mente que o impacto visual causado pela imagem sobre os observadores deve ter sido múltiplo e variado. Não seria sensato e nem honesto elencar apenas um. No entanto, também precisamos ter consciência de que dificilmente poderíamos apresentar todas as possibilidades desse tipo de impacto, uma vez que também estamos limitados pelo distanciamento cultural e temporal que temos do contexto, por mais conhecimento que tenhamos sobre o assunto. Talvez, descobertas futuras abram novas possibilidades.

\section{Considerações finais}

Levando em consideração o que abordamos neste artigo, podemos dizer que foram identificados nos diversos elementos que compõem a imagem de Dea Brigantia, tanto no que tange à figura quanto à inscrição, vestígios de interação cultural entre os "romanos" e os demais povos que compunham o Império. Da mesma forma, pudemos observar alguns aspectos do fluxo de organização de ação ritual. Afinal, construir uma imagem religiosa antropomórfica em suporte estável não era um costume bretão/celta, mas romano (Webster, 2015, p. 131). Embora de raiz indígena, a divindade foi retratada em uma imagem que remete a uma série de elementos que faziam parte da cosmovisão do

\footnotetext{
${ }^{48}$ Alguns exemplos desses que apresentam ódio aos romanos são Venúcio, Carataco e Boudica.
} 
mundo greco-romano, ou seja, romanizada. Da mesma maneira, a relação com outras formas de religiosidade, como o culto às Matronas característico do vale do Reno, parece ter sido significativa.

Em relação à função da imagem, parece que, além do caráter religioso/ritualístico, ela também poderia ter uma função político/militar, visto que a figuração, além de apresentar algumas características relacionadas à guerra, também possui elementos que apontam para um suposto domínio territorial, celebrando um triunfo sobre os inimigos do Império. É provável que a escultura tenha sido financiada por algum romano de alta patente. Conforme a leitura da inscrição, o fato de Amandus ter um grau legionário e ter "cumprido ordem de comando" aponta para isso. Como vimos, há a possibilidade dessa ordem ter vindo primeiramente da divindade, através de uma epifania, ou ter sido orientada por algum oficial ${ }^{49}$.

Não podemos saber exatamente quem eram os adoradores de Dea Brigantia, mas é provável que ela tenha sido cultuada tanto por brigantes romanizados, quanto por cidadãos romanos vindos de outras partes do Império, mas que reconheciam Dea Brigantia como uma divindade tutelar. Para os primeiros, é possível que fosse uma maneira de facilitar a permanência e propagação de um elemento da religiosidade autóctone. Para os últimos, o culto à Dea Brigantia poderia ser uma forma de conquistar a divindade daquele lugar, assim como parte de seus seguidores. Afinal, uma aproximação religiosa poderia significar não apenas o favor de uma divindade, mas também uma redução de barreiras entre os romanos e os demais povos conquistados.

Outra coisa que não podemos negar é que a imagem de Dea Brigantia deve ter causado impacto sobre a população local. No entanto, não é possível pensarmos isso de maneira generalizada, visto que os bretões poderiam ter reações e sentimentos diferentes, dependendo do grupo no qual estivessem inseridos e de seus interesses pessoais. Assim, não é possível chegar a uma conclusão geral sobre isso. Apenas podemos conjecturar sobre quem poderia ter acesso a ela. Como vimos, esse impacto deve ter ocorrido de maneiras e intensidades diferentes, de acordo com as características de cada indivíduo e grupo social que pode ter tido contato com a imagem. Ela pode ter causado indignação nos inimigos de Roma, estranheza naqueles que, embora estivessem habituados com a divindade, não estavam familiarizados com aquele tipo de representação, e uma sensação de identificação e maior compreensão dos símbolos para os novos cidadãos do Império.

\footnotetext{
${ }^{49}$ Os oficiais romanos realizavam os serviços religiosos para seu grupo.
} 
Outro ponto estabelecido foi a impossibilidade da datação sugerida anteriormente por Jolliffe (1941). Ainda que o culto à Brigantia possa ter sido incentivado pela casa imperial romana (Henig, 2005, p. 68) nos períodos dos governos de Septímio Severo e Caracala, ou seja, entre os anos 193 e 217 d.C., esta datação não se adequa à imagem de Dea Brigantia de Birrens, já que, como vimos anteriormente, não há nenhuma evidência arqueológica que sustente uma ocupação em Blatobulgium após o ano de 184 d.C. (Robertson, 1975). Assim, isso reforça a nossa ideia de que a imagem tenha sido construída por um membro da Legio VI Victrix em um recorte temporal do período Antonino, entre os anos de 138 e 161 d.C., baseado nas evidências arqueológicas sobre a presença da Legio VI Victrix em Blatobulgium, datadas daquele período (Robertson, 1975, p. 280). Não devemos descartar por completo a possibilidade de a imagem ter sido construída em outros anos de ocupação de Blatobulgium, no entanto, a possibilidade de ter ocorrido durante o período Antonino parece mais consistente.

Por fim, pensamos que este tema não se esgota aqui. Novas possibilidades de pesquisa, como a relação com outras evidências arqueológicas do culto de Brigantia na Britânia podem ser abertas, visto que evidências de Brigantia na Britânia aparecem em pelo menos nove inscrições conhecidas ${ }^{50}$. Um estudo comparativo poderia identificar similaridades e diferenças entre esses documentos. Outra possibilidade seria estabelecer um paralelo entre as manifestações religiosas de Blatobulgium com a de outros pontos de ocupação romana nas adjacências da Muralha de Adriano, ou até mesmo com outras zonas de fronteira do Império Romano. Como vemos, são muitas as possibilidades e desafios.

Recebido: $27 / 08 / 2020$

Aprovado: $21 / 09 / 2020$

${ }^{50}$ Cf. RIB 630; RIB 628; RIB 1053; RIB 1131; RIB 627; RIB 2066; RIB 623; RIB 3504; RIB 3332. 
Mare Nostrum, ano 2021, v. 12, n. 1 .

\section{REFERÊNCIAS BIBLIOGRÁFICAS}

Fontes

Gellius, A (1927). The Attic Nights. English Translation by Rolfe, J. C. Cambridge: Harvard University Press. Disponível em: <http://www.perseus.tufts.edu/hopper/text?doc=Perseus\%3atext\%3a2007.01.0072 $>$. Acesso em 14 jun. 2019.

Pausanias (1903). Pausaniae Graeciae Descriptio. Leipzig, Teubner, 3 vols. Disponível em:

$<$ https://www.perseus.tufts.edu/hopper/text?doc=Perseus\%3atext\%3a1999.01.015 9>. Acesso em: 14 jun. 2019.

Tacitus, C (1900). De Vita Iulii Agricolae. In Furneaux, H. (Ed.). Opera Minora. Cornelius Tacitus. Oxford: Clarendon Press. Disponível em: <http://www.perseus.tufts.edu/hopper/text?doc=Perseus:text:1999.02.0084>. Acesso em: 26 mar. 2019.

Tacitus, C (1911). Historiae. Charles Dennis Fisher (Ed.). Oxford: Clarendon Press. Disponível em: <http://www.perseus.tufts.edu/hopper/text?doc=Perseus:text:1999.02.0079>. Acesso em: 26 mar. 2019.

\section{Obras}

Barrow, G. W. S. (1989) The Tribes of North Britain revisited. In Proceedings of the Society of Antiquaries of Scotland, 119, 161-163.

Birley, E. (Org.) (1937). Excavations at Birrens, 1936-1937. In Proceedings of the Society of the Antiquaries of Scotland, 72, 275-347.

Christison, D. (1896). Account of the excavation of Birrens, a Roman station in Annnandale, undertaken by the Society of Antiquaries of Scotland. In Proceedings of the Society of the Antiquaries of Scotland, 30, 81-199.

Crooks, S. (2012) Cult Stones of Ancient Cyprus. Journal of Prehistoric Religion. 23, $25-44$.

Cunliffe, B. (2013). Britain Begins. Oxford: Oxford University Press.

D’Encarnação, J. (2010). Epigrafia: as pedras que falam. Coimbra: Imprensa da Universidade de Coimbra. 
Eliade, M. (2020). Tratado de história das religiões. São Paulo: Editora WMF Martins Fontes, 2016.

Garraffoni, R. S. Romanos. In Funari, P.P. (Org.). As religiões que o mundo esqueceu: como egípcios, gregos, celtas, astecas e outros povos cultuavam seus deuses (pp. 53-65). São Paulo: Contexto.

Gimbutas, M. (1999). The living goddesses. Berkeley and Los Angeles: University of California Press.

Gray, J. M. (Ed.) (1892). Memoirs of the life of Sir John Clerk of Penicuik, baronet, baron of the Exchequer, extracted by himself from his own journals, 1676-1755. Edinburgh: University Press.

Green, M. A. (1996). Celtic Goddesses: Warriors, Virgins, and Mothers. New York: George Braziller.

Green, M. A. (2006). Gallo-British Deities and their Shrines. In Todd, M. A Companion to Roman Britain (pp. 193-219). Oxford: Blackwell.

Guarinello, N. L. (2010). Ordem, integração e fronteiras no Império Romano. Um ensaio. Mare Nostrum, 1, 113-127.

Halbwachs, M. (1990). Memória individual e memória coletiva. In Halbwachs, M. A memória coletiva (pp. 25-52). São Paulo: Vértice.

Hartley, B. R., \& Fitts, R. L. (1988). The Brigantes. Gloucester: Alan Sutton.

Henig, M. (2003). The Art of Roman Britain. London: Taylor \& Francis e-Library.

Henig, M. (2005). Religion in Roman Britain. London: Taylor \& Francis e-Library.

Hingley, R. (2005). Globalizing Roman Culture. Unity, Diversity and Empire. London and New York: Routledge.

Hingley, R. (2010). O Imperialismo Romano. Novas Perspectivas a partir da Bretanha. Trad. L.C.G. Pinto. Org. R.S. Garraffoni, P.P.A. Funari, R. Pinto. São Paulo: Anablume Editora.

Jolliffe, N. (1941). Dea Brigantia. London: The Archaeological Journal, 98, 36-61.

Kaizer, T. (2007). Religion in the Roman East. In Rüpke, J. (Ed.). A Companion to Roman Religion (pp. 446-456). Oxford: Blackwell.

Keppie, L. (1994). Roman inscriptions and sculpture from Birrens: A Review. In Transactions of the Dumfriesshire and Galloway Natural History and Antiquarian Society, 69, 35-51.

Lorenz, K. (2016). Ancient Mythological Images and their Interpretation. An Introduction to Iconology, Semiotics, and Image Studies in Classical Art History. Cambridge: Cambridge University Press. 
McGrath, S. (2015). Brigantia: Goddess of the North. Wabush: Boreal Publications.

Mendes, N. M. (2006). O Sistema Político do Principado. In Mendes, N. M., \& Silva, G. V. (Orgs.). Repensando o Império Romano: perspectiva socioeconômica, política e cultural (pp. 21-52). Rio de Janeiro: Mauad; Vitória, ES: EDUFES.

Miller, S. N. (1937). 'Note on an Inscription from Birrens (Dumfriesshire)'. In Journal of Roman Studies, 27, 208-209.

Monaghan, P. (2004). The Encyclopedia of Celtic Mythology and Folklore. New York: Facts On File, Inc..

Moulakis, A. (2000). Editor's Introduction. In Moulakis, A. (Ed.). The collected works of Eric Voegelin, v. 15 (p. 30). Columbia and London: University of Missouri Press.

Nora, P. (2008). Pierre Nora en Le lieux de mémoire. Montevideo: Ediciones Trilce.

Ottaway, P. (2013). Roman York. Stroud: The History Press.

Panofsky, E. (2009). O Significado das Artes Visuais. São Paulo: Perspectiva.

Platt, V. Epiphanies (2015). In Eidinow, E., \& Kindt, J. (Ed.). The Oxford Handbook of Greek Religion (pp. 491-504). Oxford: Oxford University Press.

Robertson, A. S. (1975). Birrens (Blatobulgium). Edinburgh: T. and A. Constable LTD..

Rowland, I. D. (2014). Vitruvius and his influence. In Ulrich, R. B., \& Quenemoen, C. K. (Ed.). A Companion to Roman Architecture (pp. 412-425). Oxford: Blackwell, p. 412-425.

Stolte, B. H. (1986). Die religiösen Verhältnisse in Niedergermanien. In ANRW, II.18(1), 591-671.

Webster, J. (2015). A Dirty Window on the Iron Age? Recent Developments in the Archaeology of Pre-Roman Celtic Religion. In Bergholm, Alexandra, \& Ritari, Katja. (Ed.) Understanding Celtic Religion Revisiting the Pagan Past (pp. 121154). Cardiff: University of Wales Press.

Webster, J. (1997). A negotiated syncretism: readings on the development of RomanoCeltic religion. In Mattingly, D. J. (Ed.) Dialogues in Roman Imperialism (pp. 165184). (Journal of Roman archaeology, supplementary series 23) Portsmouth, Rhode Island.

Wilk, S. R. (2000). Medusa: solving the mystery of the gorgon. Oxford: Oxford University Press.

Woolf, G. (1998). Becoming Roman: the origins of provincial civilization in Gaul. Cambridge: University Press.

Woolf, G. (1997). Beyond Romans and natives. In World Archaeology, 28(3), Culture Contact and Colonialism, 339-350. 
Woolf, G. (2003). Local Cult in Imperial Context: The Matronae Revisited. In Romanization und Resistenz in Plastik, Architektur und Inschriften der Provinzen des Imperium Romanum Neue Funde und Forschungen: Akten des VII Internationalen Colloquiums über Probleme des Provinzialrömischen Kunstschaffen. Edited by Peter Noelke, Beate Schneider and Friedericke NaumannSteckner (pp. 131-138). Mainz: Verlag Philipp von Zabern.

Woolf, G. (2016). Only connect? Network analysis and religious change in the Roman World. In Hélade, 2(2), 43-58.

Woolf, G. (2012). Rome - An Empire's Story. Oxford: University Press. (Edição brasileira: São Paulo: Editora Cultrix, 2017.)

Wright, B. (2011). Brigid: Goddess, Druidess and Saint. Stroud: The History Press. 
Mare Nostrum, ano 2021, v. 12, n. 1.

\section{BRIGANTIA FROM BIRRENS: \\ CULTURAL INTERACTIONS IN FRONTIER ZONE OF \\ ROMAN BRITAIN}

\section{ABSTRACT}

This article aims to do an analysis of the image of Dea Brigantia from Birrens, in Britain, most likely dated from the 2nd century AD. For this, it addresses its material, its context, its composition and its elements and their meanings in an approach that encompasses both the image and the inscription that form the visual work. Possible connections with other forms of worship, traces of cultural interactions and the possible impacts on the Briton indigenous population are also investigated.

\section{KEYWORDS}

Brigantia; Roman Britain; Hadrian's Wall; Religion; Roman Empire. 